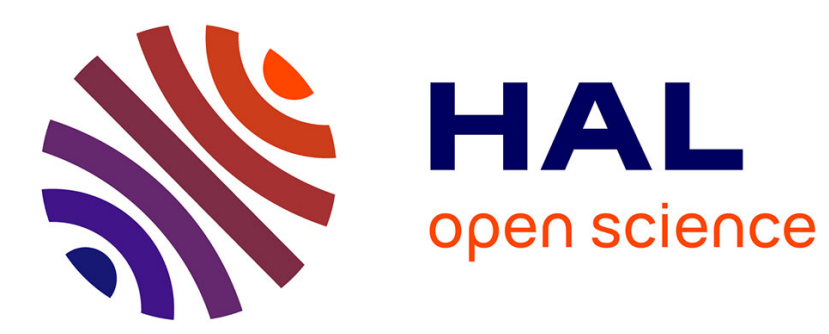

\title{
Guidelines for designing highly concentrated electrolytes for low temperature applications
}

Guillaume Ah-Lung, Benjamin Flamme, Fouad Ghamouss, Manuel Maréchal, Johan Jacquemin

\section{- To cite this version:}

Guillaume Ah-Lung, Benjamin Flamme, Fouad Ghamouss, Manuel Maréchal, Johan Jacquemin. Guidelines for designing highly concentrated electrolytes for low temperature applications. Chemical Communications, 2020, 56 (68), pp.9830-9833. 10.1039/d0cc03963b . hal-03066939

\section{HAL Id: hal-03066939 \\ https://hal.science/hal-03066939}

Submitted on 17 Dec 2020

HAL is a multi-disciplinary open access archive for the deposit and dissemination of scientific research documents, whether they are published or not. The documents may come from teaching and research institutions in France or abroad, or from public or private research centers.
L'archive ouverte pluridisciplinaire HAL, est destinée au dépôt et à la diffusion de documents scientifiques de niveau recherche, publiés ou non, émanant des établissements d'enseignement et de recherche français ou étrangers, des laboratoires publics ou privés. 


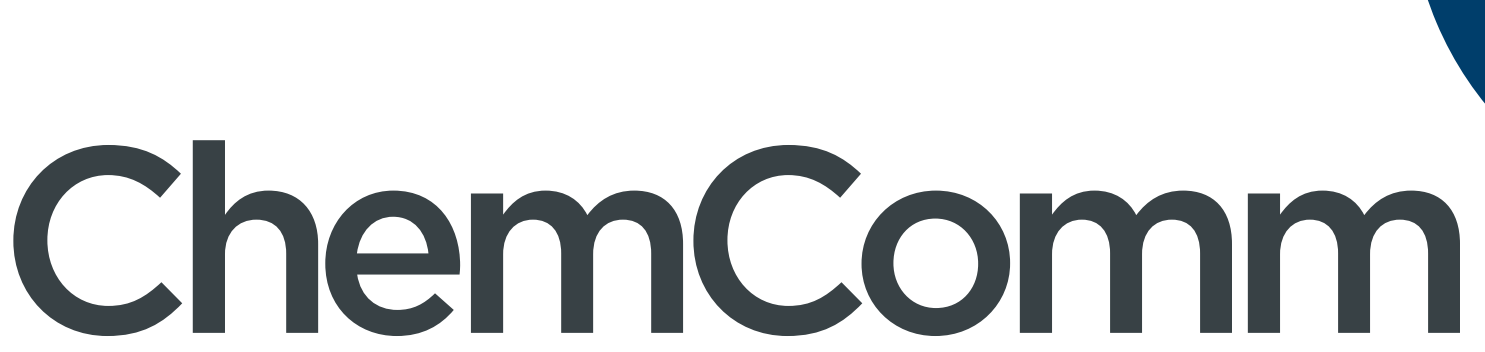

Chemical Communications

\section{Accepted Manuscript}

This article can be cited before page numbers have been issued, to do this please use: G. Ah-lung, B. Flamme, F. Ghamouss, M. G. Maréchal and J. Jacquemin, Chem. Commun., 2020, DOI:

\subsection{9/D0CC03963B.}
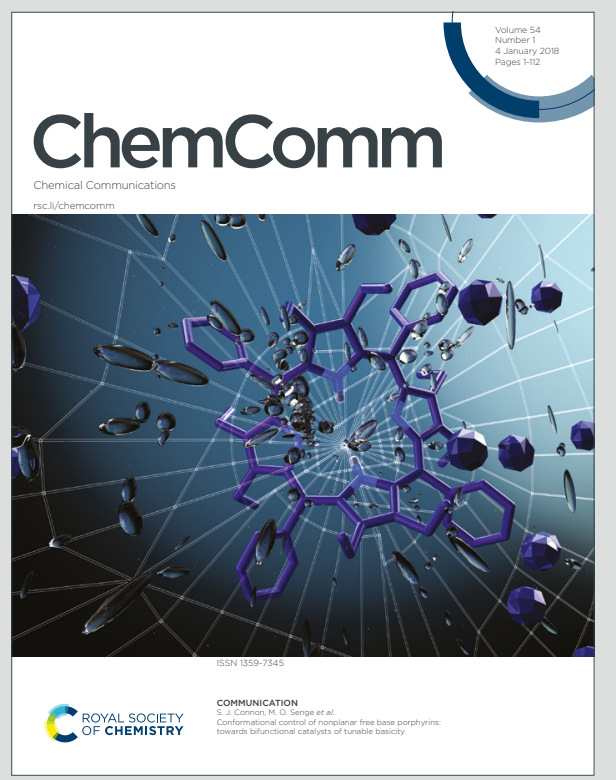

This is an Accepted Manuscript, which has been through the Royal Society of Chemistry peer review process and has been accepted for publication.

Accepted Manuscripts are published online shortly after acceptance, before technical editing, formatting and proof reading. Using this free service, authors can make their results available to the community, in citable form, before we publish the edited article. We will replace this Accepted Manuscript with the edited and formatted Advance Article as soon as it is available.

You can find more information about Accepted Manuscripts in the Information for Authors.

Please note that technical editing may introduce minor changes to the text and/or graphics, which may alter content. The journal's standard Terms \& Conditions and the Ethical guidelines still apply. In no event shall the Royal Society of Chemistry be held responsible for any errors or omissions in this Accepted Manuscript or any consequences arising from the use of any information it contains. 


\section{COMMUNICATION}

\section{Guidelines for Designing Highly Concentrated Electrolyte for Low Temperature Applications}

Received 00th January 20xx, Accepted 00th January 20xx DOI: $10.1039 / \times 0 \times x 00000 x$

\author{
Guillaume Ah-lung, ${ }^{a}$ Benjamin Flamme, ${ }^{a}$ Fouad Ghamouss, ${ }^{a, b}$ Manuel Maréchal, c \\ and Johan Jacquemin, $* a, b$
}

The redefinition of commonly named "water-in-salt" clarifies the operating temperatures of the state-of-the-art LiTFSI-based aqueous solutions. An in-depth study shows its mismatch for low temperature applications. Contrariwise, the recommended strategy is to design electrolyte at an invariant composition, as exemplified with the eutectic water/ $/ \mathrm{LiNO}_{3}$ able to electrochemically cycle down to $-23^{\circ} \mathrm{C}$

For over 30 years, scientists strive to design safer electrolytic solutions able to substitute actual benchmarks containing noxious volatile organic solvents. Several solutions were proposed by formulating alternative electrolytes for various electrochemical energy storage applications (metal-ion batteries, supercapacitors, etc.) using ionic liquids (IL), ${ }^{1,2}$ deep eutectic solvents (DES) ${ }^{3-5}$ or, more recently, water-in-salt (WIS) solutions. ${ }^{6}$ However, a proper definition and evaluation of each class of these potential candidates are still actively discussed or even controversial. While, an IL is very well defined as a low temperature molten salt with a melting point below $100^{\circ} \mathrm{C},{ }^{7}$ no scientific consensus is yet approved on the definition for neither a DES nor a WIS-based solution, to date. The former could be easily defined thanks to thermodynamic formalisms by either showing the non-ideality of its solid-liquid phase diagram revealing a deeper liquid range than expected using classical ideal mixing laws or by properly calculating the activity coefficient of each mixed species in solution..$^{8,9}$ However, the "WIS" concept is even more confusing explaining why this work has been solely devoted on this novel class of alternative electrolytes for electrochemical energy storage applications.

\footnotetext{
a. Laboratoire PCM2E, Université de Tours, Parc de Grandmont, 37200 Tours, France.E-mail: jj@univ-tours.fr

b. Materials Science and Nano-engineering (MSN) Department. Mohammed VI Polytechnic University (UM6P), Lot 660 - Hay Moulay Rachid, 43150, Benguerir Morocco.

c. Univ. Grenoble Alpes, CNRS, CEA, IRIG-SyMMES, 38000 Grenoble, France.

† Electronic Supplementary Information (ESI) available: Experimental details and supporting figures, including DSC, SWAXS, electrochemical results. See DOI: $10.1039 / \times 0 \times x 00000 x$
}

To the best of our knowledge, the term WIS was firstly reported by electrochemists, whom are mainly working by mass when formulating an electrolyte, as "more salt" than "water" is "present" in the solution. This is, of course, caused by the difference between the molecular weights of water and used molten salt, (i.e. often a factor higher than 10) leading to an illusion than more "salt", which is always inappropriately judged as a "solute", than "solvent" is constituting the solution. This was even argued to affect the interactions, stability and electrochemical windows of the electrolytic solution. By looking at this concept within a different eye position, each WIS solution reported in the literature based on a single salt dissolved in water shall be, more properly, defined as a highly concentrated electrolytic solution, as water is generally the main solvent (e.g. with a mole fraction often higher than 0.7 ) of the solution. However, the particularity of the WIS electrolyte is related to the absence of free water molecule as all species are solvated in solution. ${ }^{10}$ This concept is already known as a century ago Bjerrum proposed a so-called "concept of ion association in electrolyte solution", 11 based on which one can easily argue than more than four molecules of water could interact with $\mathrm{a} \mathrm{Li}^{+}$ cation in solution, for example. However, one interesting point, not very well covered to date in the literature, is that the water molecule, as any polar associative solvent, could interact either with cation and anion through strong electron/hydrogen donor or acceptor sites. ${ }^{12,13}$ For this main reason, this series of WIS should be more appropriately identified as Water Interacting Strongly with Salt(s) electrolytes, WISS, as claimed therein. This ability differs to that observed in the case of benchmark electrolytes based on polar non-associative solvents ${ }^{14}$ either in metal-ion batteries or supercapacitors. This difference on anion-solvent interactions could explain why no free solvent molecule exists in a $21 \mathrm{~m} \mathrm{LiTFSI} \mathrm{aqueous} \mathrm{solution} \mathrm{(e.g.} \mathrm{a} \mathrm{solution}$ containing 21 moles of LiTFSI dissolved in $1 \mathrm{~kg}$ of pure water, i.e. $x_{\text {water }}=0.725$, denoted herein as LiTFSI $21 \mathrm{~m}$ ), a contrario of a solution containing $1 \mathrm{~mol} \cdot \mathrm{dm}^{-3}$ of $\mathrm{Et}_{4} \mathrm{NBF}_{4}$ in acetonitrile (e.g. $x_{\text {acetonitrile }} \sim 0.9$ at $25^{\circ} \mathrm{C}$ ), for example.

On the one hand, the WISS-series based on the LiTFSI salt has been originally intensively studied, particularly because of its 
wide electrochemical stability window, which is extended when the LiTFSI concentration raise up..$^{15-18}$ On the other hand, some studies tried to extend its operating range to low temperatures showing that the LiTFSI $21 \mathrm{~m}$ can be even cycled down to -20 ${ }^{\circ} \mathrm{C} .{ }^{19,20}$ However, according to solid-liquid LiTFSI- $\mathrm{H}_{2} \mathrm{O}$ binary phase diagram available in the literature, ${ }^{21-22}$ an electrolyte with a $x_{\text {LiTFSI }}=0.275$ (e.g. LiTFSI $21 \mathrm{~m}$ ) is purely liquid only above at least $25{ }^{\circ} \mathrm{C}$, making it a surprising choice for low temperature applications. Actually, the composition that would be the most suitable for such applications, is the eutectic one, which is located at $5.16 \mathrm{~m}\left(x_{\text {LITFSI }}=0.085\right)$ and at a eutectic temperature, $T_{\mathrm{E}}$, of $-43.4{ }^{\circ} \mathrm{C}$, or eventually the congruent melting crystal LiTFSI $\cdot\left(\mathrm{H}_{2} \mathrm{O}\right)_{4}$ solvate $\left(x_{\text {LiTFSI }}=0.2\right.$ and $\left.T_{\mathrm{m}}=-8.7^{\circ} \mathrm{C}\right)$ according to ref. [22]. However, at $x_{\text {LITFSI }}=0.085$, one can argue if this electrolyte could be still so called as a WISS electrolyte able to be used over an extended electrochemical stability window. Another key factor to point out herein is the preparation of the electrolyte, which must be done under rigorous conditions, particularly because of the use of LiTFSI. This salt is greatly hygroscopic (Fig. S1 of ESI) and has to be stored in dry condition, typically in an argon filled glove box even why using it to formulate solely aqueous solutions. Otherwise the contamination caused by the water, present in atmosphere, can strongly decrease the final salt concentration in the electrolyte, leading to inaccurate results and wrong conclusions. In this context, a "salt-in-water" LiTFSI $21 \mathrm{~m}$ electrolyte was prepared under strict conditions (see ESI) and studied, firstly, by Differential Scanning Calorimetry (DSC) and Small- and WideAngle X-ray Scattering (SWAXS) in order to determine the operating thermal limits of this electrolyte. Those limits will be, in a second time, validated in electric-double-layer-capacitor (EDLC)-type electrochemical devices.

During DSC preliminary studies, differences in thermograms were observed for the same electrolyte depending on the temperature of the preparation room (Figs. S3-S4 of ESI). Main results are combined in the Fig. 1 depicting the modified thermal behaviour of the same electrolyte stored at $20{ }^{\circ} \mathrm{C}$ (inhomogeneous, blue curve) and $30{ }^{\circ} \mathrm{C}$ (homogeneous, red curve). In addition, a typical DSC trace of LiTFSI $21 \mathrm{~m}$ is supported with corresponding SWAXS patterns at key temperatures (green curve). As further depicted in the Fig. S2 of $\mathrm{ESI}$, a broad melting point, ending at $27^{\circ} \mathrm{C}$, is exhibited by the homogeneous LiTFSI $21 \mathrm{~m}$, revealing the coexistence of solid and liquid phases until this value. The solid phase is composed of $\mathrm{H}_{2} \mathrm{O}$.LiTFSI $\left(x_{\text {LiTFSI }}=0.5\right.$ ) leading to a liquid phase with a LiTFSI molality inferior to $21 \mathrm{~m}$, shifting its crystallization to lower temperatures down to $-50^{\circ} \mathrm{C}$. The way to escape this behaviour is to avoid temperature below its liquidus or to heat a too cold electrolyte above $43^{\circ} \mathrm{C}$ to melt the coexisting solid phase (Fig. S3b). SWAXS experiments have confirmed a detectable presence of the solid phase up to $18{ }^{\circ} \mathrm{C}$ (Fig. S5). The temperature difference with the reported liquidus is easily explained by the almost stationary experimental conditions of the X-Ray diffraction and the dynamic DSC scan $\left(2{ }^{\circ} \mathrm{C} \cdot \mathrm{min}^{-1}\right)$. To summarize, LiTFSI $21 \mathrm{~m}$ has to be prepared and stored above 25 ${ }^{\circ} \mathrm{C}$ to be homogeneous and to exhibit its intrinsic properties. Moreover, based on our thermal studies, these electrolytes should not be able to operate below its crystallization temperature (i.e. $\left.-3^{\circ} \mathrm{C}\right)$.

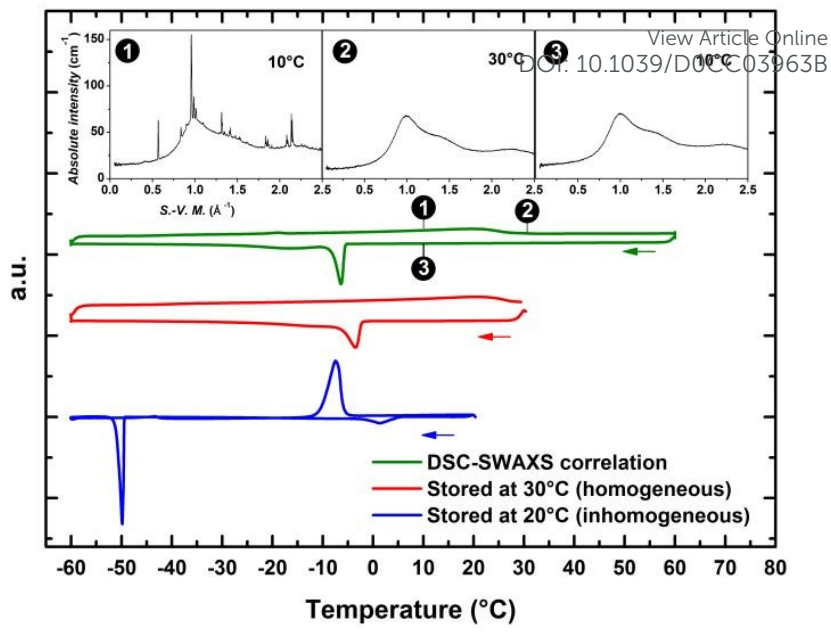

Fig. 1: DSC thermograms of homogeneous and inhomogeneous LiTFSI $21 \mathrm{~m}$ and a correlation between DSC scan and SWAXS patterns (S-V. M. = Scattering-vector modulus $q)$.

By continuing based on our conclusions, two series of activatedcarbon-based symmetric (A.C.//A.C.) electrochemical capacitors containing LiTFSI $21 \mathrm{~m}$ were prepared and stored above $25{ }^{\circ} \mathrm{C}$ (homogeneous electrolyte), and below $23{ }^{\circ} \mathrm{C}$ (inhomogeneous electrolyte). The supercapacitors were then cycled at $10 \mathrm{mV} \cdot \mathrm{s}^{-1}$ and at different temperatures to study their electrochemical behaviours (Fig. S6). As expected for the homogeneous electrolyte (Fig. S6a), at $0{ }^{\circ} \mathrm{C}$, the electrochemical signal started to be affected by the cell resistance mainly due to the increase of the electrolyte resistance. The impact of the cell resistance is even more pronounced at $-10{ }^{\circ} \mathrm{C}$, when the electrolyte finally crystallizes before the $20^{\text {th }}$ cyclic voltammetry (CV). Indeed, the first cycle corresponds to the highest ion concentration in the diffusion layer ensuring a sufficient ions accumulation at the interface allowing the charge of EDLCs even if a crystallization occurred. As the number of cycles increases, the thickness of the diffusion layer increases leading to a decrease of the capacitive current and consequently to a flat CV due to crystallization. This confirms our conclusions on the lower operating limit of $-3{ }^{\circ} \mathrm{C}$ for the LiTFSI $21 \mathrm{~m}$, which cannot operate below this temperature in an electrochemical device requesting high rate like EDLC. However, this experimental observation highlights the importance of reporting all set experimental conditions in detail to avoid any false conclusion. Surprisingly, concerning the inhomogeneous electrolyte, exactly the same electrochemical behaviour was observed (Fig. S6b). Despite the DSC analysis, this electrolyte containing a liquid phase with a lower molality (see ESI) was unable to stay in the liquid state below $-10{ }^{\circ} \mathrm{C}$ showing a flat $\mathrm{CV}$ at this temperature. Our main hypothesis is that another factor must be considered, i.e. the electrochemical device itself. Similar to the mesocarbon microbeads particles used to help crystallization during thermal studies, the components of the capacitor in contact with the electrolyte (porous electrodes, their distance and the separator) can play this role, creating propitious nucleation sites in addition with micro-gradients of concentrations affording an early crystallization process. The preparation and the utilisation of LiTFSI $21 \mathrm{~m}$ WISS is not only very sensitive to the purity and storage of its components, but also to the storage and the preparation temperature of the 
obtained electrolyte. However, this work reveals that the presence of a portion of $\mathrm{H}_{2} \mathrm{O} \cdot \mathrm{LiTFSI}$ solid crystals does not seem to greatly alter the overall performances of EDLC, as well as, its working temperature range. Finally, despite a marked interest related to the extended potential window and the intrinsic properties of this WISS, its composition does not allow it to be considered as a relevant candidate for low temperature applications as sub-phases may coexist. In this context, it is greatly preferable to work with electrolytes based on an invariant point like eutectic compositions or in some case congruent melting crystal solvates, for which the solid-liquid transition is reversibly occurring without any composition change as any pure component. Consequently, the second part of this work was focused on $\mathrm{LiNO}_{3}$ aqueous electrolyte. $\mathrm{LiNO}_{3}$ presents the highest solubility in water $\left(50.5 \mathrm{wt} . \%\right.$ at $\left.25^{\circ} \mathrm{C}\right)$ among classic alkali salts, ${ }^{25}$ offering thus the possibility of a eutectic point at a high salt concentration. This was confirmed by its solid-liquid binary phase diagram. ${ }^{26}$ Moreover, relatively large electrochemical stability windows close to $2.20 \mathrm{~V}$ and $2.55 \mathrm{~V}$ were reported for highly concentrated aqueous electrolytes containing 6.5 and 62 wt.\% of $\mathrm{LiNO}_{3}$, respectively. ${ }^{18}$ Its eutectic point is located at 24.5 wt.\% of $\mathrm{LiNO}_{3}$ salt (corresponding to $4.2 \mathrm{~mol} \cdot \mathrm{dm}^{-3}$ or $4.7 \mathrm{~m}$ ) with a melting temperature at $-22.9^{\circ} \mathrm{C} .{ }^{26}$ Such a composition will combine low temperature applications with wide operating voltage (at least $2.20 \mathrm{~V}^{18}$ ). The same strategy, as used for LiTFSI, was then applied for preparing and thus analysing this electrolyte (see ESI). First, DSC were performed on $\mathrm{LiNO}_{3}$ aqueous electrolyte prepared at the eutectic composition, without separator (used therein as reference) and with several separators commonly used in electrochemical applications (Whatman, glass microfibers series ${ }^{27}$ ) to verify hypotheses claimed into the literature and addressed thanks to LiTFSI results.

First of all, the thermogram of $\mathrm{LiNO}_{3}$ electrolyte without separator (Fig. 2, black curve) confirms that the eutectic composition is well obtained. This is visualized on the DSC trace by a single crystallization peak and a single melting point reached at $-23^{\circ} \mathrm{C}$, which is in perfect agreement with the phase diagram. ${ }^{26}$ Furthermore, and as suspected, the separator selection has an impact on the thermal behaviours of the electrolyte when decreasing the temperature in its metastable region (i.e. for temperature below its melting point); while, a similar melting temperature is observed in each case, demonstrating the thermal and chemical stability of the electrolyte whatever the selected separator. However, as shown in Fig. 2, two crystallization peaks with no invariant point are observed in DSC traces of the electrolyte with a separator suggesting the presence of liquids in two different environments. This can be related to the presence of free electrolyte onto the surface (first crystallization peak at approx. $-40^{\circ} \mathrm{C}$ which resembles to that observed without separator) and some confined into the separator (second crystallization peak below $-50{ }^{\circ} \mathrm{C}$ ). However, only the interaction changes with the presence of the separator could explain the temperature shift observed within the first crystallization peak. In fact, this temperature shift seems to be strongly affected by the separator porosity as shown in Figs. 2 and S7.

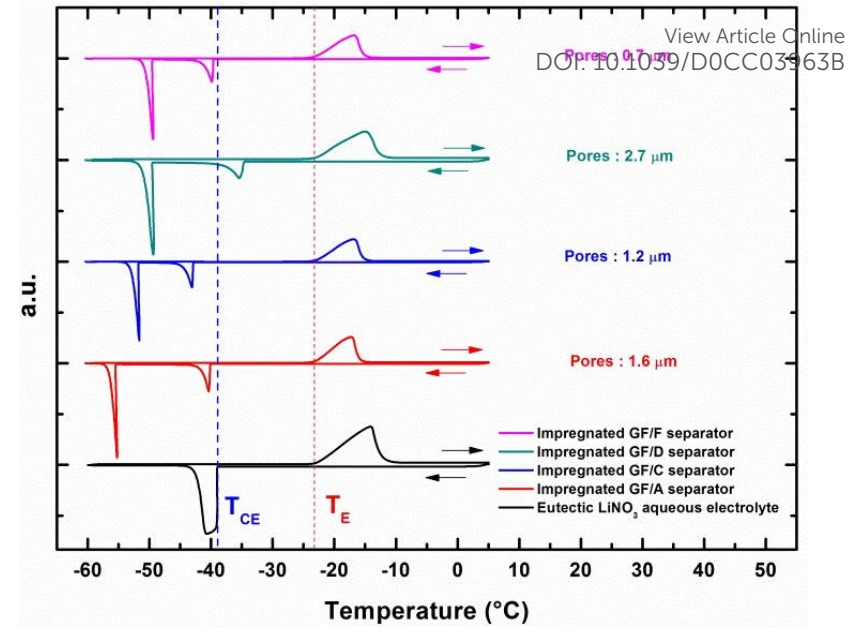

Fig. 2 DSC traces of eutectic $\mathrm{LiNO}_{3}$ aqueous electrolyte without separator and with several classic GF-based separators.

By looking at each DSC trace, an EDLC device should be even cycle at $-40^{\circ} \mathrm{C}$, if no other parameters affect its cyclability. The lowest-temperature crystallization is obtained when the electrolyte is impregnated into GF/C, with $1.2-\mu \mathrm{m}$-pore size, which also presents the smaller gap between the two crystallization peaks (Fig. 2, blue curve). As a result, GF/C was recognized as the separator to be used during the electrochemical studies. However, even in the case of the electrolyte crystallization, such a device must be able to restart cycling after reaching again a temperature above the eutectic temperature ( $T_{\mathrm{E}}$ in Fig. 2). CV measurements were then performed in coin cells using the eutectic $\mathrm{LiNO}_{3}$ aqueous electrolyte with GF/C separator in A.C.//A.C. configuration at $+20{ }^{\circ} \mathrm{C},-20{ }^{\circ} \mathrm{C},-30{ }^{\circ} \mathrm{C}$ prior to be heated back to $+20{ }^{\circ} \mathrm{C}$. Two significant and relevant results collected from identical EDLC devices have been collected as depicted in Fig. 3. First of all, in each case, a rectangular shape is obtained indicating typical EDLC reversible capacitive behaviour. Interestingly, some coin cells easily cycled even at $-30{ }^{\circ} \mathrm{C}$ conserving their initial capacitance $\left(28 \mathrm{~F} \cdot \mathrm{g}^{-1}\right.$ ) represented by near stackable CVs (Fig. 3a), which has never been reported in pure aqueous electrolyte, to date.

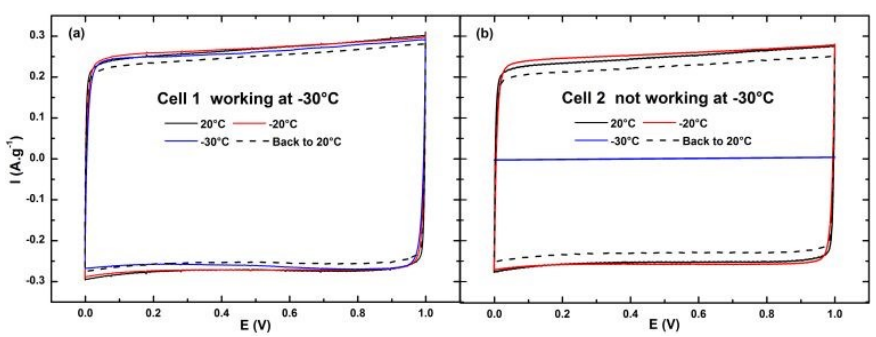

Fig. 3 Cyclic voltammograms at $10 \mathrm{mV} \cdot \mathrm{s}^{-1}$ of A.C.//A.C. identical coin cells cycled with eutectic $\mathrm{LiNO}_{3}$ aqueous electrolyte and $\mathrm{GF} / \mathrm{C}$ separators consecutively at $20{ }^{\circ} \mathrm{C}, \quad-20{ }^{\circ} \mathrm{C}$, $-30^{\circ} \mathrm{C}$ and then $20^{\circ} \mathrm{C}$. Example of a coin cell operating at $-30{ }^{\circ} \mathrm{C}$ (a) and of another identical coin cell not operating at $-30^{\circ} \mathrm{C}$ (b) 
Randomly, other coin cells quickly crystallized after reaching $-30{ }^{\circ} \mathrm{C}$, as identified by their flat $\mathrm{CV}$ at $-30{ }^{\circ} \mathrm{C}$ (Fig. 3b). These opposite results could be explained by the fact that at $-30{ }^{\circ} \mathrm{C}$, the eutectic $\mathrm{LiNO}_{3}$ aqueous electrolyte is in a supercooled state, i.e. metastable and thus very sensitive to any stimulation (cycling, scan rate, heating/cooling rate, surface tension, etc.) inducing, according to Le Chatelier principle, the electrolyte crystallization. Interestingly, no matter if the crystallization occurred or not, all devices recovered full performances when the devices are set back to $20^{\circ} \mathrm{C}$. i.e. by crossing the melting temperature, highlighting the importance of selecting an electrolyte at a eutectic (invariant) composition. Such results also indicate a suitable wettability between the electrolyte and the separator even after crystallisation-liquification cycles. However, even if $-40{ }^{\circ} \mathrm{C}$ cannot be reached, due to the metastability of the supercooling, the proposed eutectic $\mathrm{LiNO}_{3}$ aqueous electrolyte could be used at temperature down to, at least, $-23{ }^{\circ} \mathrm{C}$ in symmetric A.C.//A.C. capacitors. Furthermore, even if a crystallization occurs, a simple temperature increase above its melting point will lead to the reactivation of the device as no composition change is occurring between liquid and solid states in the case of a eutectic. This exemplifies the net benefit to formulate an electrolyte at a composition leading to an invariant point to avoid the coexistence of solid and liquid phases. According to the metastable nature of the supercooled electrolyte and interfacial electrode/electrolyte interactions, the cycling should be limited to: i) the fusion temperature of invariant point, while for ii) variant composition, such as LiTFSI $21 \mathrm{~m}$, cycling should be limited to temperature above its liquidus temperature avoiding the coexistence of solid-liquid phases. Other well-defined and characterized eutectic-based electrolytes could in fact be formulated and used in any device including asymmetrical/hybrid supercapacitors, or metal-ion batteries for temperature down to, at least, their liquidus. Finally, if a lower temperature is required for applications in extreme environments, an additive (i.e. another salt ${ }^{24,28}$ or cosolvent ${ }^{29,30}$ ), to obtain neoteric ternary electrolytes, could considerably decrease the melting temperature of the electrolyte. Formulating a multinary components-based electrolyte at an invariant composition with concentration limiting the presence of free water (by mimicking calculations above-mentioned for DES) seems to be a relevant strategy, which could combine relatively large operating voltage (energy density) and low temperature applications, rather than a trial and error formulation method based on salt(s) saturated solutions.

\section{Conflicts of interest}

There are no conflicts to declare.

\section{Acknowledgments}

This research was developed within the scope of the project S3CAP (ANR-18-ASMA-0001) financed by the ANR and was also supported thanks to the Lavoisier program of the Region Centre Val de Loire. B. Corso (ICSM) and Dr. S. Lequien (IRIG/MEM/SGX) are gratefully acknowledged for their continual help with the $X$ ray scattering.

\section{Notes and references}

View Article Online DOI. 10.1039/DOcC03963B

1 M. Watanabe, M. L. Thomas, S. Zhang, K. Ueno, T. Yasuda and K. Dokko, Chem. Rev., 2017, 117, 7190-7239.

2 N. Dubouis, C. Park, M. Deschamps, S. Abdelghani-Idrissi, M. Kanduč, A. Colin, M. Salanne, J. Dzubiella, A. Grimaud and B. Rotenberg, ACS Cent. Sci., 2019, 5, 640-643.

3 A. M. Navarro-Suárez and P. Johansson, J. Electrochem. Soc., 2020, 167, 070511.

4 M. K. Tran, M.-T. F. Rodrigues, K. Kato, G. Babu and P. M. Ajayan, Nat. Energy, 2019, 4, 339-345.

5 C. J. Clarke, W.-C. Tu, O. Levers, A. Bröhl and J. P. Hallett, Chem. Rev., 2018, 118, 747-800.

6 M. Chen, G. Feng and R. Qiao, Curr. Opin. Colloid Interface Sci., 2020, 47, 99-110.

7 N. V. Plechkova and K. R. Seddon, Chem. Soc. Rev., 2008, 37, 123-150

8 L. J. B. M. Kollau, M. Vis, A. van den Bruinhorst, G. de With and R. Tuinier, Pure Appl. Chem., 2019, 91, 1341-1349.

9 M. A. R. Martins, S. P. Pinho and J. A. P. Coutinho, J. Sol. Chem., 2019, 48, 962-982.

10 O. Borodin, L. Suo, M. Gobet, X. Ren, F. Wang, A. Faraone, J. Peng, M. Olguin, M. Schroeder, M. S. Ding, E. Gobrogge, A. von Wald Cresce, S. Munoz, J. A. Dura, S. Greenbaum, C. Wang and K. Xu, ACS Nano, 2017, 11, 10462-10471.

11 N. Bjerrum, Kgl. Dansk. Vidensk. Selskab, Mat. Fys. Medd., $1926,7,1$.

12 V. Gutmann, The Donor-Acceptor Approach to Molecular Interactions, Springer, New York, $1^{\text {st }}$ edn., 1978.

13 S. Han, RSC Adv., 2019, 9, 609-619.

14 H.-W. Wang, T. R. Graham, E. Mamontov, K. Page, A. G. Stack and C. I. Pearce, J. Phys. Chem. Lett. 2019, 10, 3318-3325.

15 S. F. Lux, L. Terborg, O. Hachmöller, T. Placke, H.-W. Meyer, S. Passerini, M. Winter and P. Novák, J. Electrochem. Soc., 2013, 160, A1694-A1700.

16 L. Suo, O. Borodin, T. Gao, M. Olguin, J. Ho, X. Fan, C. Luo, C. Wang and K. Xu, Science, 2015, 350, 938-943.

17 Y. Yokoyama, T. Fukutsuka, K. Miyazaki and T. Abe, J. Electrochem. Soc., 2018, 165, A3299-A3303.

18 J. Zheng, G. Tan, P. Shan, T. Liu, J. Hu, Y. Feng, L. Yang, M. Zhang, Z. Chen, Y. Lin, J. Lu, J. C. Neuefeind, Y. Ren, K. Amine, L.-W. Wang, K. Xu and F. Pan, Chem., 2018, 4, 2872-2882.

19 L. Suo, F. Han, X. Fan, H. Liu, K. Xu and C. Wang, J. Mater. Chem. A, 2016, 4, 6639-6644.

$20 \mathrm{H}$. Wang, H. Zhang, Y. Cheng, K. Feng, X. Li and H. Zhang, Electrochim. Acta, 2018, 278, 279-289.

21 G. Perron, D. Brouillette and J. E. Desnoyers, Can. J. Chem., 1997, 75, 1608-1614.

22 M. S. Ding and K. Xu, J. Phys. Chem. C, 2018, 122, 1662416629.

23 J. L. Nowinski, P. Lightfoot and P. G. Bruce, J. Mater. Chem., $1994,4,1579-1580$.

24 D. Reber, R-S. Kühnel and C. Battaglia, ACS Mater. Lett., 2019, 1, 44-51.

25 O. Söhnel and P. Novotny, J. Chem. Eng. Data, 1988, 1, 4955.

26 A. N. Campbell and R. A. Bailey, Can. J. Chem., 1958, 36, 518536.

27 C. F. J. Francis, I. L. Kyratzis and A. S. Best, Adv. Mater., 2020, 1904205.

28 M. Becker, R-S. Kühnel and C. Battaglia, Chem. Commun., 2019, 55, 12032-12035.

29 Q. Abbas and F. Béguin, J. Power Sources, 2016, 318, 235241.

30 X. Lu, R. J. Jiménez-Riobóo, D. Leech, M. C. Gutiérrez, M. L. Ferrer and F. del Monte, ACS Appl. Mater. Interfaces, 2020, 12, 29181-29193. 